\title{
XXVI. THE PART PLAYED BY INSECTS IN THE EPIDEMIOLOGY OF PLAGUE.
}

By D. T. VERJBITSKI, M.D.

(From the Laboratory of the Emperor Alexander $I$, and of the Imperial Institute of Experimental Medicine at St Petersburg.)

\section{Introduction to Translation.}

Dr Verjbitski's experiments were made in 1902-3 at Cronstadt and St Petersburg and the results were presented as a thesis for the degree of Doctor of Medicine to the University of St Petersburg in 1904. Owing to the fact that the thesis was written in the Russian language and not published in any scientific journal this important research has apparently been lost sight of, and has also for the most part escaped abstraction by the journals of Western Europe ${ }^{1}$. In consequence it has not as far as we are aware been referred to by any of the workers on the subject since its presentation.

During the early part of last year the Committee succeeded in obtaining a copy of Dr Verjbitski's thesis which has been kindly transslated for them by Mrs J. B. Leathes. Dr Verjbitski's experiments appeared to the Committee so admirably conceived and executed, and the results obtained by him so important in relation to the spread of the plague through the agency of insects, particularly fleas, that they communicated with the author requesting permission to publish an account of them as an appendix to one of the reports of the work of the Plague Commission.

Dr Verjbitski's researches covered much of the ground subsequently traversed by the Commission, although the particular species of fleas worked with in the two instances were not identical. According to Verjbitski the common flea captured off rats in Cronstadt was Typhlopsylla musculi, the more usual host of which is, in other localities, the

1 The attention of the Committee was drawn to the work by a short abstract in the Journal de Physiologie et de Pathologie gênêrale, vol. vir. 1906, p. 387. 


\section{Reports on Plague Investigations in India}

mouse. This flea was not found to bite human beings, so that the full epidemiological significance of Dr Verjbitski's work was not apparent.

In preparing Dr Verjbitski's papers for publication in English, some minor omissions and alterations have been considered advisable. The historical introduction has been omitted, as the literature on the subject received full treatment in these reports (Journal of Hygiene, vol. VI. p. 425). In the original thesis a very full and detailed account of the pathological findings at the post-mortem examinations of the various animals which succumbed to infection is given. In the translation this has usually been omitted and the facts resumed by some such statement as:- "the post-mortem presented a characteristic picture of plague infection." Further, in the original, the author, after having adequately presented the results of his experiments in tabular form, subsequently reiterated them at considerable length in the text. This, however, appeared in most cases to be unnecessary and in the translation the Tables have been usually allowed to speak for themselves. Otherwise the text has been as faithfully preserved as was consistent with the different formation of the two languages.

\section{Part I. Experiments with Fleas.}

In order to ascertain the part played by parasites in the spread of plague infection, I chose for my experiments fleas and bugs as being the parasites which chiefly frequent the human being. In my experiments with fleas, rats were employed in view of the established connection between plague epidemics amongst people and plague epidemics amongst rats.

Once the possibility of infection by the bites of fleas which are infected with plague microbes was proved, the transference of plague from rat to rat and from rat to man and vice versa, would easily explain both plague epidemics amongst rats and the connection between the latter and the plague epidemics amongst people.

The first questions which arose were:-did rat fleas bite men, and did human fleas bite rats? The flea which is mostly found on rats is Typhlopsylla musculi'

To answer these questions the following series of experiments were undertaken.

1 Dr Verjbitski is presumably referring to his experience in Cronstadt. The commonest rat flea in most parts of Europe is Ceratophyllus fasciatus, and in India and most subtropical countries Pulex cheopis of Rothschild (see Journal of Hygiene, vol. vr. 1906, p. 483). Ed. 
(1) Fleas were combed out of grey rats into a high cylinder and were gathered in a test tube, which was applied with its opening downwards to the wrist of a human being. In the majority of cases the fleas did not bite, but sometimes positive results were obtained, and careful examination of the fleas made it clear that these bites were not occasioned by rat fleas but by Pulex canis. In 40 experiments confined to Typhlopsylla musculi these fleas, even after lengthy previous starvation (from $10-40$ hours), did not bite men.

(2) Human fleas, $P$. irritans, enclosed in test tubes were in the above manner applied to the shaved inner surface of the hind leg of a grey rat. Under these circumstances they invariably fed and the more readily the longer the fleas were allowed to starve before the experiment.

We have just mentioned that, besides ordinary rat fleas, $P$. canis was observed on grey rats; this circumstance made me turn my attention to fleas found on domestic animals and their relation to rats and man.

For these experiments I took $\operatorname{dog}$ and cat fleas, $P$. canis (Ctenocephalus novemdentatus) and $P$. felis (Ctenocephalus enneodus) as being those belonging to domestic animals which stand in most intimate relation to man. The macro- and microscopical appearances which I observed in these fleas ( $P$. irritans, $P$. canis, and $P$. felis), corresponded entirely with the description of these parasites given by Professor Brandt and Neveu-Lemaire whose papers I had at my disposal whilst investigating the above species of fleas.

In order to make clear the relation of $\mathrm{dog}$ and cat fleas as occasional parasites of rats and man, I made the following experiment.

(3) Fleas collected from dogs and cats were starved for 10 hours, and allowed to bite both rat and man. In both cases a positive result was obtained; dog and cat fleas immediately attacked both man and rat leaving very clearly defined bites. Therefore $P$. canis and $P$. felis bite both man and rat, and the fact that they were found on rats shows that they had lived on the latter as casual parasites.

I have investigated whether $P$. irritans, $P$. canis, and $P$. felis, which were artificially brought into contact with rats, would continue to live on them, and if so for how long. This experiment was done in the following way:

(4) Fleas collected from cats and dogs were placed in high cylinders, 15 in each. There were 10 cylinders. Cylinders 1 to 5 contained cat-fleas; 6 to 10 dog-fleas. Into each cylinder a grey rat 
was put. After half an hour all the rats were taken out, but no fleas were left in the cylinders. The rats were afterwards put into cages. After two days the fleas were combed out into glass pots from the rats 1 and 6 , and the number of $P$. canis and $P$. felis was counted; after four days the same was done with rats 2 and 7 ; after six days with 3 and 8 , and so on. The number of fleas obtained was probably smaller than that actually present, as it was not found possible to comb out all the fleas from the rats.

\section{TABLE I.}

$\begin{array}{ccccccccc}\text { Species of fleas } & \begin{array}{c}\text { Numbers } \\ \text { of rats }\end{array} & \text { 1 day } & 4 \text { days } & 6 \text { days } & 8 \text { days } & 10 \text { days } & 12 \text { days } & 14 \text { days } \\ \text { Pulex felis } & 1 & 6 & - & - & - & - & - & - \\ " & 2 & - & 4 & - & - & - & - & - \\ " & 3 & - & - & 5 & - & - & - & - \\ " & 4 & - & - & - & 2 & - & - & - \\ " & 5 & - & - & - & - & - & - & 0 \\ \text { Pulex canis } & 6 & 5 & - & - & - & - & - & - \\ " & 7 & - & 7 & - & - & - & - & - \\ " & 8 & - & - & 4 & - & - & - & - \\ " & 9 & - & - & - & - & - & 1 & - \\ " & 10 & - & - & - & - & - & - & 0\end{array}$

Therefore, on the 8th-12th day from the beginning of the experiment it was still possible to find $P$. canis and $P$. felis on the rats, which indicates that these fleas can live on rats. The same experiment was repeated with $P$. irritans.

(5) Ten human fleas were put on each of two rats. After four days three were found on the first, and after eight days two fleas on the second. This proves that $P$. irritans can also live on the rat.

If under artificial conditions $P$. irritans, $P$. canis, and $P$. felis, can live on the rat it was interesting to ascertain if they.lived there under natural conditions. Having at my disposal a number of grey rats for experiments, I combed the fleas out of them and determined their species. Altogether I looked over 300 rats, on 37 of which I found $P$. canis in addition to the ordinary Typhlopsylla musculi. The number on each rat fluctuated between one and four. The rest of the rats only harboured Typhlopsylla musculi; on none of them could I find $P$. irritans or $P$. felis.

From the above experiments I conclude:

1. The rat flea Typhlopsylla musculi does not bite men.

2. Human fleas bite rats. 
3. Fleas of dogs and cats bite both men and rats.

4. Human fleas and fleas of dogs and cats can live as parasites on rats.

This latter circumstance, in connection with the fact that cat and dog fleas also attack man, makes it clear that under certain conditions transmission of these fleas from rat to man and vice versa is quite possible. Such favourable conditions appear for instance in the conditions surrounding the lives of the Kirguises (nomad race of Siberia), where frequent plague epidemics have been observed. People and domestic animals live together in dirty earth huts, with absence of ventilation, overcrowding, and insufficient light. The mats which cover the floor of these huts are teeming with fleas, partly $P$. irritans, but chiefly $P$. canis. If we take into consideration that during the winter the life of the Kirguise is spent on these mats, that they sit, eat, and sleep on them, it is easy to understand the possibility of these fleas indiscriminately living both on man and on the rats of which there is an abundance in these huts.

The investigations of Ogata, the German Commission, and others, have determined that fleas caught on dead rats, and rats ill with plague, may contain virulent plague microbes. My experiments always gave a positive result where the investigation concerned rat fleas which had been collected from dying or just dead rats, and also in the cases where human fleas and fleas of domestic animals had sucked the blood from a rat dying from plague. In every case I found plague microbes which corresponded in their virulence to the culture with which the animal had been inoculated. I carried out my experiments in the following way.

\section{Experiment $I$.}

Rat fleas collected from a rat which had died from plague, and $P$. irritans, $P$. canis, and $P$. felis, which had sucked the blood of a rat dying from plague, were crushed between two glasses and carefully smeared over the surface; these smears were fixed and stained with eosin and methylene blue. The microscopical examination showed blood corpuscles more or less altered according to the time since ingestion. Amongst these corpuscles were found single oval bi-polar staining bacilli which did not stain by Gram. Their number in most cases was not large, one, two or perhaps three in the field of vision. In these preparations one could also observe other forms of 


\section{Reports on Plague Investigations in India}

bacilli, but more often cocci of different sizes. More than 100 investigations of this kind were made, and always with the same result.

In order to definitely establish the fact that the observed microbe was that of plague, it was necessary to cultivate it.

\section{Experiment II.}

Fleas of the species Typhlopsylla musculi, P. irritans, P. canis, and $P$. felis were allowed to suck the blood of a rat dying of plague and then crushed between two glasses. The glasses were afterwards immersed into tubes containing alkaline broth, which in their turn were put for 24 hours into the thermostat. After 24 hours, growth accompanied by opacity of the broth was observed. Microscopical examination showed that the culture was not pure. Sub-culture upon agar gave :

1. Round colonies resembling seeds with a festooned edge, which consisted sometimes of short bi-polar staining bacilli.

2. Yellow or white colonies more or less opaque which consisted either of cocci or of bacilli of different sizes.

No. 1 on all nutrient media gave a growth typical of plague. On inoculating rats, white mice and guinea pigs with this culture death invariably took place and the post-mortem presented a characteristic pathologico-anatomical picture of plague. The microseopical investigation of the growth on agar and in broth of both the blood and organs of these animals established the presence of plague bacilli in pure culture. Cultures obtained from the other colonies (No. 2) consisted either of cocci or of bacilli. Their inoculation had no effect on animals except occasional suppuration at the spot of inoculation. These microbes are commonly found in the intestine or on the surface of the flea's body.

Cultures of plague from fleas, which had sucked the blood of rats dying of plague, were also obtained in another way.

\section{Experiment III.}

Fleas collected from a rat dying of plague were put into a test tube with physiological salt solution, and were crushed by means of a glass rod and carefully mixed with the salt solution. The emulsion obtained in this way was used for inoculating rats. The result of these inoculations was not always the same and depended partly on the virulence of the culture which had killed the rat whose parasites these fleas had 
been, and partly upon the number of crushed fleas used for inoculation. The more virulent the culture, the less fleas sufficed to bring about infection. As will be seen from the following table, in the beginning of the experiments when the rats on which the fleas fed were killed by very weak cultures, only those rats died which had been inoculated with an emulsion of 10 fleas. As the culture grew more virulent fewer fleas were required, and when the minimal lethal dose of the culture corresponded to $\frac{1}{500000}$ c.c. of a 24 hours' broth culture, the infection and death of a rat could be obtained by injecting subcutaneously the emulsion of one flea.

\section{TABLE II.}

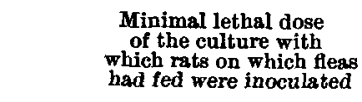

Ito c.c. 24 hours broth culture

10000 c.c. 24 hours broth culture

1000

100कण0 c.c. 24 hours broth culture

$500^{1} 000$ c.c. 24 hours broth culture

\begin{tabular}{|c|c|c|}
\hline $\begin{array}{l}\text { Number of fleas collected } \\
\text { on rats which were } \\
\text { crushed and inoculated } \\
\text { into a fresh rat }\end{array}$ & $\begin{array}{c}\text { Result } \\
\text { on the } \\
\text { fresh rat }\end{array}$ & $\begin{array}{l}\text { Time } \\
\text { of death }\end{array}$ \\
\hline 4 & lived & \\
\hline 6 & lived & \\
\hline 8 & lived & \\
\hline 10 & died & 110 hours \\
\hline 2 & lived & \\
\hline 4 & lived & \\
\hline 6 & died & 104 hours \\
\hline 8 & died & 98 hours \\
\hline 1 & lived & \\
\hline 2 & lived & \\
\hline $\mathbf{3}$ & died & 101 hours \\
\hline 4 & died & 119 hours \\
\hline 1 & died & 100 hours \\
\hline 1 & lived & \\
\hline 2 & died & 97 hours \\
\hline 2 & died & 102 hours \\
\hline
\end{tabular}

The post-mortem examination of the rats killed in this way showed haemorrhagic infiltration at the place of inoculation, buboes, fatty liver and haemorrhages of the serous membranes. Cultures of the blood and organs on agar or in broth always gave a pure growth of plague bacilli. Analogous results were obtained when instead of rat fleas, $P$. irritans, $P$. canis, and $P$. felis were taken.

As it would seem not improbable that the fleas can under certain circumstances transmit plague infection, I next ascertained how long the plague microbe can live in the body of a flea, or rather, how long after it has entered the body of a flea it could still be detected. The necessary nourishment of the flea was in the meantime effected by feeding upon a healthy animal. The results of the following experiments serve to answer this question. 


\author{
Experiment $I V$.
}

Rat fleas, and $P$. irritans, $P$. canis, and $P$. felis were placed each in separate test tubes and after previous starvation were allowed to bite rats dying from plague. The rat was put into a beaker, the inner surface of one of its hind legs was carefully shaved, and the opening of the test tube was carefully applied to it and inverted. Each test tube contained two or three fleas. After feeding the test tubes were reversed and closed with cotton wool and put into a cupboard at the temperature of from $16-18^{\circ} \mathrm{C}$. On the following day one of each kind of flea was crushed between two sterilised glasses, one of which was afterwards fixed and stained for microscopical examination, while the second was used to obtain a broth culture.

The fleas remaining in the test tubes were in the same manner fed again on another, but this time a healthy rat: 24 hours after, one of each was again taken for both microscopical and cultural purposes, and the remaining fleas were again fed on another healthy rat, etc. Fifteen of each species of fleas were used for this experiment, and the investigation was continued for 13 days.

The subsequent history of the healthy rats upon which the fleas fed I shall reserve for future discussion, but the answer to the question how long the bacilli remain alive within the flea is given in Table III.

TABLE III.

On which day after allowing fleas to bite a rat dying of plague the microscopical and bacteriological investigation took place.

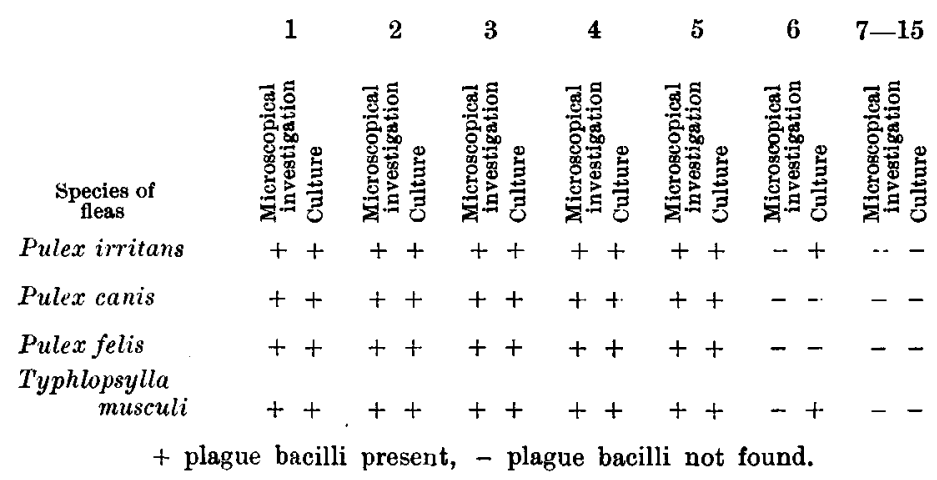

As the plague microbe did not lose its vitality after five to six days in the body of the flea, it was interesting to determine how 
this sojourn acted on its virulence, that is to say, whether the culture obtained from the plague microbes out of the fleas corresponded to the virulence of the culture with which the rat was infected. The following experiment was undertaken with a view to determining this point.

\section{Experiment $V$.}

Four rats were infected with cultures of different virulence:-

1. With cultures whose minimal lethal dose corresponded to $\frac{1}{10000}$ c.c. of 24 hours' broth culture.

2. With cultures whose minimal lethal dose corresponded to $\frac{1}{100000}$ c.c.

3. With cultures whose minimal lethal dose corresponded to $\frac{1}{500000}$ c.c.

4. With cultures whose minimal lethal dose corresponded to 1000000 c.c.

When these rats were beginning to die, fleas were applied to them :-

To the first rat, specimens of Typhlopsylla musculi.

To the second rat, specimens of $P$. irritans.

To the third rat, specimens of $P$. canis.

To the fourth rat, specimens of $P$. felis.

TABLE IV.

The fleas had 4 days
ago sucked the blood

of a rat killed

by a culture of

lethal dose was equal to

I000 c.c.

$1 \frac{2}{10000}$ c.c.

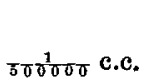

$100 \frac{1}{0000}$ c.c.

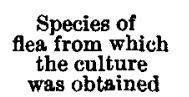

Typhlopsylla musculi

Pulex

irritans

Pulex

canis

Pulex

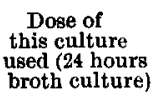

Nos. of
ratg Results
of roth eu

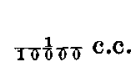

( 1

2
3

100бण c.c. $\left\{\begin{array}{l}1 \\ 2 \\ 3\end{array}\right.$

ธ0000 c.c. $\left\{\begin{array}{l}1 \\ 2 \\ 3\end{array}\right.$

1000000 c.c. $\left\{\begin{array}{l}1 \\ 2 \\ 3\end{array}\right.$

+ rat died, - rat lived.

After this, these fleas were fed during four days on healthy animals, and on the fifth day one of each was crushed between two glasses, the latter were immersed into test tubes of broth and placed in the thermo- 
stat. After 24 hours the organism was obtained by sub-culture. In this way four plague cultures were obtained from the fleas, and the 24 hours' cultures in broth were tested with regard to virulence. The results are given in Table IV.

We see therefore that the plague microbe had retained its vitality, and that its virulence did not practically differ from the virulence of the culture with which the animal had been infected.

\section{Experiment VI.}

Six of each of the four species of fleas were applied to a rat dying of plague. Two of each kind were immediately afterwards drowned in a test tube containing broth. After two days two of each species were again treated in the same manner. The remaining fleas received the same treatment after four days, although in the meantime they had died, as during absolute starvation the fleas of the above kinds do not live more than two to two and a half days. All these test tubes were put for 24 hours into the thermostat. Only in some cases could plague bacilli be obtained by plating. Out of the first eight cultures only four gave a positive result, viz.

Two of the test tubes which contained $P$. canis.

One of the test tubes which contained $P$. felis.

One of the test tubes which contained Typhlopsylla musculi.

The second lot of eight cultures gave only one positive result, i.e. one test tube which contained $P$. canis. The last eight cultures gave two positive results, and in both cases with $P$. canis. The positive results in these cases evidently depended on the fact that in the processes of sucking the tongue and mouth organs of the fleas retained a certain amount of infectious blood adhering to it.

The following experiment was undertaken with a view to proving how long the vitality of the plague microbe is maintained in the body of the flea under different conditions.

\section{Experiment VII.}

A number of each of the four species of fleas which had fed on a dying infected rat were subsequently starved. When they were dead, one test tube containing a corpse of each species was exposed to different conditions of moisture and temperature, and after a certain time tested for the presence of plague microbes. The conditions were the following :- 
1. The first four test tubes containing each one flea of each of the kinds were put into the thermostat at the temperature of $28-30^{\circ} \mathrm{C}$.

2. The second lot of four test tubes was subjected to the action of sunlight. The fleas treated in this manner were investigated daily.

3. The third lot of four test tubes was put into the cold cupboard with a temperature on an average of $3^{\circ} \mathrm{C}$.

4. The fourth lot of four test tubes was placed at a temperature of from -5 to $-15^{\circ} \mathrm{C}$.

5. The fifth lot of test tubes was left at room temperature in a dark cupboard.

6. To the sixth lot of test tubes was added physiological salt solution and they were then placed in the same cupboard.

7. These fleas were kept between moist sheets of filter paper and pieces of linen.

The corpses of the fleas were investigated every three days to see whether plague bacilli could be obtained from them. The results are shown in Table V.

\begin{tabular}{|c|c|c|c|c|c|c|c|}
\hline $\begin{array}{l}\text { Species } \\
\text { of fleas }\end{array}$ & $\begin{array}{l}\text { In the } \\
\text { thermostat } \\
\text { temp. } \\
28^{\circ}-30^{\circ}\end{array}$ & $\begin{array}{l}\text { Room } \\
\text { temp. } \\
14^{\circ}-16^{\circ}\end{array}$ & $\begin{array}{l}\text { Physio- } \\
\text { logical } \\
\text { alt } \\
\text { solution }\end{array}$ & $\begin{array}{l}\text { Between } \\
\text { damp sheets } \\
\text { of paper } \\
\text { and linen }\end{array}$ & $\begin{array}{l}\text { Cold } \\
\text { cupboard } \\
\text { temp. }+3^{\circ}\end{array}$ & $\begin{array}{l}\text { Under the } \\
\text { action of } \\
\text { direct rays } \\
\text { of sunlight }\end{array}$ & $\begin{array}{l}\text { Freezing } \\
-5^{\circ}-15^{\circ} \mathrm{C} .\end{array}$ \\
\hline Pulex irritans & 3 & 9 & 21 & 24 & 18 & 3 & 15 \\
\hline Pulex canis & 4 & 6 & 15 & 21 & 18 & 4 & 15 \\
\hline Pulex felis & 3 & 6 & 21 & 18 & 21 & 3 & 12 \\
\hline $\begin{array}{l}\text { Typhlopsylla } \\
\text { musculi }\end{array}$ & 2 & 9 & 18 & 21 & 15 & 3 & 18 \\
\hline
\end{tabular}

Cultures from fleas which had been kept between damp sheets of filter paper were tested for virulence on the second day from the beginning of the experiment. The rats which had infected these fleas had died from inoculation of a culture the virulence of which was $\frac{1}{1000000}$ c.c. From Table VI. it appears that the virulence had decreased to almost

TABLE VI.

Nos. of rats
1
2
3
4
5
6
7

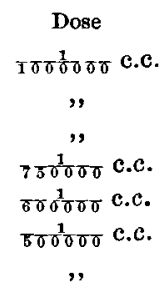

$$
\begin{gathered}
\text { Result } \\
\text { lived } \\
\text { lived } \\
\text { lived } \\
\text { lived } \\
\text { died } \\
\text { died } \\
\text { died }
\end{gathered}
$$

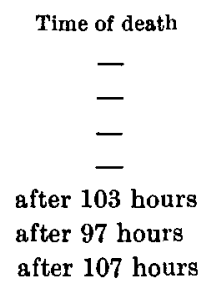


one half $\left(\frac{1}{600000}\right.$ c.c.). After passage of the culture three times through rats it regained its former virulence.

The following experiments show at what period of the illness of infected rats fleas absorbed plague microbes by sucking their blood.

\section{Experiment VIII.}

Four rats were infected with plague cultures of different strengths, and at intervals of 12 hours after infection three fleas of each of the four species were applied to them until they had fed sufficiently. These fleas were afterwards investigated microscopically and by culture. Blood from the infected rats was withdrawn at the same time and examined in the same manner. The feeding of the fleas was repeated at the above intervals until the death of the rats 72 to 108 hours after inoculation. The virulence of the culture inoculated varied somewhat, as will be seen from Table VII below, in which the results of the experiment are set out.

We see therefore that the plague microbe could be easily detected only in the fleas which contained the blood of the animal 12 to 26 hours before its death.

According to Yersin and Nuttall, flies die after feeding on a medium containing plague culture, or on organs of an infected corpse. They die sooner, the higher the temperature. The fleas, however, remained perfectly indifferent to the presence in their body of plague microbes, and if allowed to feed daily on infected rats they lived a long time both at room temperature and in the thermostat.

I next endeavoured to ascertain :

1. Whether plague microbes are present in the excretions of such fleas.

2. If so, during what length of time after application to an infected animal and subsequent feeding on healthy ones they could be found.

3. Whether the vitality and virulence of the plague microbe are preserved after its transit through the digestive canal of the flea.

\section{Experiment $I X$.}

One flea of each of the four species was placed in a small sterilised tube and applied to a moribund infected rat. They remained in this test tube for 24 hours, and after that were placed in others. Their faeces, which remained on the glass of the first test tubes in the form of black spots, were mixed with a drop of sterilised water at the end of 
a platinum wire. The liquid obtained in this manner was spread on the surface of a slide which was afterwards dried, fixed and stained with methylene blue and eosin. Another portion of the liquid was poured into broth tubes and put for 24 hours in the thermostat.

After 24 hours the fleas were again placed in fresh test tubes and their faeces again investigated. It was only possible to do this during two days, as the unfed fleas died on the third day. The microscopical examination of the excreta gave the following results:

Amongst the amorphous masses which were faintly stained pink by eosin and small unstained balls with double outlines which reminded one of fat drops, oval bi-polar bacilli occurred which were stained by methylene blue. There were from three to ten bacilli in the field of vision; amongst these bacilli one could sometimes observe microbes of other forms, e.g. cocci of different sizes, but these were only present in insignificant numbers.

The broth cultures showed a growth after 24 hours. This growth did not show the characteristic appearances of plague cultures, and the microscopical investigation revealed that, in addition to oval bi-polar staining rods and chains which did not stain by Gram, cocci and also long thin non-motile rods were present.

Cultures of the excretions on agar revealed:

1. A considerable number of round-shaped colonies of grey colour which under the microscope looked like small seeds with double festooned edges, and which consisted of short bi-polar staining bacilli.

2. Smaller quantities of opaque colonies either white or yellow, and once green, consisting of bacilli and cocci of different sizes.

The first colonies when grown on agar and broth gave typical growths of plague. The second colonies I did not investigate, as they did not present any resemblance to plague colonies.

The faeces of infected fleas of all four species were investigated over 100 times and both on the first and second day invariably gave a positive result.

The following experiment was undertaken to determine after how many days the faeces of fleas which had been fed once on an infected animal, and subsequently on healthy rats, contain the plague microbe.

\section{Experiment $X$.}

One of each of the four species of fleas was applied after previous starvation to a dying infected rat. After 24 hours the fleas were placed in fresh test tubes and their faeces investigated in the same way as in 
Experiment IX; after that they were fed on healthy rats and their excretions examined every 24 hours. This was continued for several days with the following results.

TABLE VIII.

\begin{tabular}{|c|c|c|c|c|c|c|c|c|c|c|c|c|}
\hline \multirow{2}{*}{$\begin{array}{l}\text { Species } \\
\text { of fleas }\end{array}$} & \multirow{2}{*}{$\begin{array}{l}\text { Nos. of } \\
\text { fleas }\end{array}$} & \multicolumn{11}{|c|}{ Days after the beginning of the experiment } \\
\hline & & 1 & 2 & 3 & 4 & 5 & 6 & 7 & 8 & 9 & 10 & \\
\hline \multirow[t]{4}{*}{ Pulex irritans } & 1 & + & + & + & + & + & - & - & - & - & - & - \\
\hline & 2 & + & + & + & + & - & - & - & - & - & - & - \\
\hline & 3 & + & + & + & + & + & + & - & - & - & - & - \\
\hline & 4 & + & + & + & + & - & - & - & - & - & - & -. \\
\hline \multirow[t]{4}{*}{ Pulex canis } & 1 & + & + & - & - & - & - & - & - & - & - & - \\
\hline & 2 & + & + & + & + & + & - & - & -. & - & - & - \\
\hline & 3 & + & + & + & + & + & - & - & - & - & - & - \\
\hline & 4 & + & + & + & + & - & - & - & - & - & - & - \\
\hline \multirow[t]{4}{*}{ Pulex felis } & 1 & + & + & + & - & - & - & - & - & - & - & - \\
\hline & 2 & + & + & + & - & - & - & - & - & - & - & - \\
\hline & 3 & + & + & + & + & + & - & - & - & - & - & - \\
\hline & 4 & + & + & + & + & - & - & - & - & -- & - & - \\
\hline \multirow{4}{*}{$\begin{array}{c}\text { Typhlopsylla } \\
\text { musculi }\end{array}$} & 1 & + & + & + & + & + & - & - & - & - & - & - \\
\hline & 2 & + & + & + & + & + & + & - & - & - & - & - \\
\hline & 3 & + & + & + & + & + & + & - & - & - & - & - \\
\hline & 4 & + & + & + & + & + & - & - & - & - & - & - \\
\hline
\end{tabular}

From the results set forth in Table VIII we see that the faeces of the infected fleas did not contain any plague microbes after five to six days, and the investigation of the fleas themselves proved that they did not contain any plague microbes after this period. We are led to suppose that the plague microbe is localised in the digestive canal without spreading to the insect's tissues and other organs.

It remained to be determined if the plague microbe preserves its irulence after being passed through the digestive organs of the flea. Agar cultures obtained from the faeces of P. irritans on the seventh day following their infection were tested, and it was seen that the strength of the culture had not decreased and corresponded in its virulence to the culture which had served to infect the rat. The experiments to determine how long and under what conditions this virulence is preserved in the faeces were made subsequently together with the experiments on infected bugs, and will be detailed later.

As may be seen from Table IX inoculation not only with cultures but with the faeces of the infected fleas themselves, caused the death of rats from plague. 


\section{Experiment XI.}

The material used for inoculation in this experiment consisted of the faeces of an infected flea; they were mixed with physiological salt solution and subcutaneously injected into a rat. This was done every 24. hours, the flea being fed on healthy animals.

TABLE IX.

\begin{tabular}{|c|c|c|c|}
\hline Species & $\begin{array}{l}\text { Which day after } \\
\text { infection the } \\
\text { faeces were used } \\
\text { for inoculation }\end{array}$ & $\begin{array}{c}\text { Result } \\
\text { on rat }\end{array}$ & $\underset{\substack{\text { Time of } \\
\text { death }}}{ }$ \\
\hline \multirow[t]{6}{*}{ Pulex irritans } & 1 & + & after 84 hours \\
\hline & 2 & + & "95 , \\
\hline & 3 & + & „103 \\
\hline & 4 & + & , 97 \\
\hline & 5 & - & \\
\hline & 6 & - & \\
\hline \multirow[t]{6}{*}{ Pulex canis } & 1 & + & after 89 hours \\
\hline & 2 & + &, 103 \\
\hline & 3 & + & $" 97$, \\
\hline & 4 & + & , 101 \\
\hline & 5 & + & „ 108 \\
\hline & 6 & - & \\
\hline \multirow[t]{6}{*}{ Typhlopsylla musculi } & 1 & + & after 105 hours \\
\hline & 2 & + &,$" 113$, \\
\hline & 3 & + & $" 93$, \\
\hline & 4 & - & \\
\hline & 5 & - & \\
\hline & 6 & - & \\
\hline
\end{tabular}

These results show that a flea may excrete during three to five days a sufficient amount of plague microbes to kill a rat, but that inoculations with the faeces excreted later than five days gave a negative result. The post-mortem revealed in some cases a more, in others a less pronounced picture of plague, whilst an enormous number of plague microbes were to be observed in the blood and organs of the animal. On two occasions an abscess was observed at the point of inoculation. In the first case only yellow staphylococci could be obtained from the pus, and the rat remained alive; in the second case the pus contained plague microbes as well as yellow staphylococci, and the rat died of plague. The virulence of the culture used for infecting the rat on which the fleas were fed was $\frac{1}{1000000}$ c.c. of 24 hours' broth culture. When fleas were infected from rats which had been infected by a culture of a low virulence (M.L.D. $\frac{1}{100}$ to $\frac{1}{1000}$ c.c.) the excretions of these 
fleas did not occasion infection and death from plague, although the excretions contained plague microbes.

\section{Experiment XII.}

If a certain number of fleas are infected by feeding on a dying rat and some of them crushed and at once examined microscopically, whilst the remaining fleas are allowed to live and their faeces examined microscopically daily, we find that the number of plague microbes is certainly larger in the latter case. On counting the number of microbes visible in the field of vision in preparations made from fleas crushed immediately after infection, and comparing the numbers with those in the blood of the rat on which they had fed, we find that the more microbes are contained in the blood, the more will be found in the fleas. But it is only rarely that one succeeds in seeing more than two to three plague microbes in the field of a specimen from a crushed flea. The reason is evidently that the blood sucked by the fleas is diluted by the juices of these insects and by the physiological salt solution employed in making the preparation. Fleas which have been once fed on an infected rat, and subsequently on a healthy one, show a considerable increase of plague microbes in their faeces after 24 hours. The number of these microbes in the field of vision is generally from eight to ten, and almost the same number was observed in the faeces on the second or third day; on the fourth day, however, the number decreased to two or three in the field of vision, on the fifth and sixth day the whole preparation hardly contained three to four microbes and not always even that, and after seven to eight days there were none to be found at all. The same results were obtained with all four species of fleas.

An additional observation was made with a view to proving that the plague microbe goes on increasing in the infected fleas.

\section{Experiment XIII.}

Pulex canis were infected as usual from a dying rat. Altogether 22 fleas were used, two in each of 11 test tubes. After feeding, two of them were at once crushed, and the remaining 10 test tubes containing 20 fleas were kept, five at room temperature and five in the thermostat at $28-30^{\circ} \mathrm{C}$. The fleas were fed during the experiment on healthy animals. After every 24 hours two of each series were crushed and microscopically examined. Comparison of the number of microbes contained in the field of vision in the case of 
fleas which were crushed at once, with the number contained in the preparations of fleas kept both at room temperature and in the thermostat, showed differences. In the former preparations from one to four plague microbes were found, in the preparations on the next day from fleas kept at room temperature there were four to seven, and from those kept in the thermostat from three to twelve. There was approximately the same number of microbes in the preparations made on the second and third day. On the fourth day, in both the fleas kept at room temperature and in the thermostat, the number suddenly decreased to one or two in the former case, and three to five in the latter. In some cases plague bacilli were found on the fifth and sixth day, but they entirely disappeared on the seventh to eighth day. It was clear therefore that the plague microbes increased in the digestive canal and the intestine of the flea, and that the increase is the more evident where the infected insects have been kept at a temperature favourable to the plague microbe, i.e. in the thermostat.

\section{Experiments XIV to XVIII.}

The question now was whether infected fleas played only a passive part in transferring infectious material, or whether they could actively spread plague through living alternately on diseased and healthy animals and inoculating the latter with plague by their bites. Only a minimal quantity of plague microbes can be communicated in this way, so that infection can only take place on condition that the plague microbe injected possesses a very high degree of virulence. This was proved by the experiment made with plague cultures of a low virulence, as in no cases did infection take place through fleas which had been infected by rats inoculated with a culture, the minimal lethal dose of which was $\frac{1}{10000}$ c.c., $\frac{1}{1000 \overline{0}}$ c.c., $\frac{1}{200000}$ c.c., $\frac{1}{300000}$ c.c., or $\frac{1}{400000}$ c.c., notwithstanding that the fleas were found on bacteriological and microscopical examination to contain a number of living plague microbes. Five experiments were made. Ten rats were used for each experiment, and not one of the 50 rats died. In the nineteenth experiment the rat used for infecting the fleas was inoculated with a virulent culture, and a positive result was obtained for the first time.

\section{Experiment $X I X$.}

A rat was inoculated with plague culture the M.L.D. of which was $\frac{1}{500000}$ c.c., the quantity injected was $\frac{1}{400000}$ c.c. of broth culture. On 
the fourth day its blood was examined during the death agony, and was seen to contain a considerable number of plague microbes; the rat was afterwards placed in a beaker, the inner surface of its left hind leg carefully shaved, and fleas of the four species, which had been previously starved for 30 hours, were applied. Altogether 30 fleas of each species, two or three in each test tube, were applied. After 12 hours they were allowed in the same manner to bite the shaven surface of the leg of healthy rats. Each rat was bitten by 10 fleas of one species, so that 12 rats altogether were used in the experiment. On the sixth day one of the three rats which were bitten by infected fleas of the species $P$. canis died; the blood and organs gave cultures typical of plague. The remaining rats did not show any signs of illness.

\section{Experiment $X X$.}

A rat was infected with a plague culture, of which the minimal lethal dose was $\frac{1}{800000}$ c.c. The experiment was conducted as above. Out of 12 rats three died; one on the fifth day, which had been infected by Typhlopsylla musculi, and two, on the fifth and sixth day respectively, which had been infected by $P$. felis. The blood and the organs of all three rats revealed a large number of plague microbes.

\section{Experiment $X X I$.}

The procedure was the same as in Experiments XIX and XX except that the rat was inoculated with a broth culture, the minimal lethal dose of which was $\frac{1}{1000 \overline{00}}$ c.c. Three out of 12 rats died. Two infected by $P$. irritans died on the fourth and fifth day, and the third infected by $P$. canis died on the fifth day.

Whenever positive results were obtained in the three last experiments there was at the situation of the bites a limited oedema or infiltration surrounded by an area in which the vessels were injected and, in some cases, small haemorrhages occurred.

Experiments were next made in which the fleas were simply placed in a vessel containing a rat so that they could themselves select the situation whereon to feed. These and all the further experiments were conducted exclusively with a culture with M. L. D. $\frac{10 \frac{1}{10000}}{\text { c.c }}$ 


\section{Experiment $X X I I$.}

Ten fleas of one species were placed in a vessel containing a rat dying of plague. After six to eight hours, these fleas were removed and placed in a large cylindrical pot into which a healthy rat was afterwards placed. Generally, when the rat was taken out after half an hour there were no fleas left behind, as they had all settled on the rat. This experiment was repeated 10 times with each of the four kinds of fleas. Forty rats were used, out of which eight died.

In view of the well-known habit of fleas of leaving an animal as soon as it is dead, I made an experiment under conditions which as nearly as possible corresponded to those found in nature. I had a cage made which consisted of a zinc box, the sides of which had glass panes. Its length was $1 \frac{1}{2}$ yards, the breadth and height 1 yard. This box was divided into two halves by a wire screen with openings of $3 \mathrm{~mm}$. square; one of these halves, painted red, was reserved for infected animals, the other, painted white, for healthy ones. It was possible to entirely separate the two halves by pushing in a glass partition at 1 c.m. distance from the wire screen; it descended inside in the part where the healthy animal was kept. The bottom of the cage was made of perforated zinc, and the cage was placed upon a basin containing sublimate solution. The top of each half was separate and consisted of the very finest copper gauze, the openings of which hardly admitted the point of a needle; at all four corners were inserted movable boxes for containing solid and liquid food. The experiments were conducted in the following way.

The glass partition between the two halves was lowered, the infected rat put into one half and a healthy one into the other. A number of fleas were shaken from test tubes on to the infected rat when it was dying. After its death the glass partition was raised and the corpse allowed to remain for 24 hours in the cage; the healthy rat was removed on the next day. Not a single flea was discovered on the corpse after 24 hours; they had all settled on the healthy rat. This was especially marked in the experiments with $P$. irritans, $P$. canis, and $P$. felis.

The method followed in separating the fleas from the rat was the following: the rat was secured by means of a pair of pincers applied to its neck, and its hind legs were grasped by a hand wrapped in a towel soaked in sublimate. The animal was held over a glass jar, and carefully combed with a fine comb. The hands, rubber coat, and table on which this operation took place were soaked with sublimate. The jar was 
afterwards covered with a funnel, on the top of which was? placed a test tube; when the jar was reversed all the fleas fell down into the test tube where they were kept. Whenever it was necessary to take out a certain number of fleas, another smaller glass funnel was applied to the opening of the test tube, and the necessary number were decanted into another test tube.

\section{Experiment XXIII.}

This experiment with Typhlopsylla musculi was conducted in the cage described above. Fifteen fleas were applied to each of 10 infected rats. Out of the 10 healthy rats two died, one on the fifth and the other on the sixth day. All the fleas collected from these two rats contained plague microbes.

\section{Experiment $X X I V$.}

This was a similar experiment with fleas of the species of P. canis. Out of $\mathbf{1 0}$ healthy rats used for this experiment one died on the seventh day, and nine remained alive.

\section{Experiment $X X V$.}

A similar experiment was performed with $P$. irritans but gave a negative result. All 10 rats remained alive.

\section{Experiment $X X V I$.}

A similar experiment with $P$. felis; out of 10 rats one died on the sixth day.

These experiments establish that it is undoubtedly possible to convey plague from one rat to another by means of flea bites, though the percentage of illness and death in these cases is comparatively small.

The next experiments were performed in order to ascertain whether a wound made by non-infected fleas afforded a means of entrance, under favourable conditions, for any plague microbes coming into contact with it. Or whether those bites were only fatal when inflicted by infected fleas which forcibly introduced plague microbes under the skin at a certain depth below it.

\section{Experiment XXVII.}

From one to five fleas (not infected) were applied to the shaved surface of the hind leg of a number of rats. Pronounced traces of bites 
were left on the skin, which disappeared on pressure and appeared again when the pressure was removed. The situations of the bites were smeared with

1. A 24 hours' broth culture of plague bacilli.

2. The same culture diluted $1-100$.

3. The blood and organs of an infected animal.

4. Faeces of infected fleas.

A soft brush was used for spreading the different preparations so as to avoid any pressure and rubbing of the skin, and the material brought into contact with the place of the bites was allowed to dry on the skin. The rats were shaved the day before the experiment so as to allow the irritation of the skin to subside; the shaving itself was conducted very carefully and no animal which had received even the slightest cut was used. It must be mentioned that in this experiment only half the

\begin{tabular}{|c|c|c|c|c|}
\hline $\begin{array}{l}\text { Material used for } \\
\text { smearing the fleas' bites: }\end{array}$ & $\begin{array}{l}\text { No. of fleas which } \\
\text { inflicted bites }\end{array}$ & $\begin{array}{l}\text { Result } \\
\text { in rat }\end{array}$ & \multicolumn{2}{|c|}{$\begin{array}{c}\text { Time } \\
\text { of death }\end{array}$} \\
\hline \multirow{5}{*}{$\begin{array}{l}24 \text { hours broth culture of plague } \\
\text { bacilli }\end{array}$} & 1 & - & & \\
\hline & 2 & + & 95 & hours \\
\hline & 3 & - & & \\
\hline & 4 & + & 112 & \\
\hline & 5 & + & 101 & ", \\
\hline \multirow{5}{*}{$\begin{array}{l}24 \text { hours broth culture diluted } \\
1-100\end{array}$} & $\mathbf{1}$ & - & & \\
\hline & 2 & - & & \\
\hline & $\mathbf{3}$ & - & & \\
\hline & 4 & - & & \\
\hline & 5 & + & 93 & hours \\
\hline \multirow{5}{*}{$\begin{array}{l}\text { Blood of a rat which died from } \\
\text { plague }\end{array}$} & 1 & - & & \\
\hline & 2 & + & 87 & hours \\
\hline & 3 & + & 94 & , \\
\hline & 4 & + & 101 & , \\
\hline & $\mathbf{5}$ & + & 77 &, \\
\hline \multirow{5}{*}{$\begin{array}{l}\text { Pulp from a kidney of an in- } \\
\text { fected rat }\end{array}$} & 1 & - & & \\
\hline & 2 & - & & \\
\hline & 3 & + & & hours \\
\hline & 4 & - & & \\
\hline & $\mathbf{5}$ & + & 78 & $"$ \\
\hline \multirow[t]{5}{*}{ Excretions of infected fleas } & 1 & - & & \\
\hline & 2 & + & 99 & hours \\
\hline & $\mathbf{3}$ & - & & \\
\hline & 4 & + & 80 & ", \\
\hline & 5 & - & & \\
\hline
\end{tabular}


animals were treated by shaving, in the others the hair was simply cut short: this proved quite immaterial to the fleas since they bit as readily in the one case as in the other.

The results obtained are set forth in Table $\mathrm{X}$.

The results show that it is possible to infect animals in all the above mentioned ways. The fleas evidently inflicted sufficient injury to the skin to allow the plague microbes to penetrate it. In no case could the infection be brought about unless more than one flea had inflicted their bites. Positive results were obtained when the bites of two fleas were smeared with a plague culture of which the minimal lethal dose was $\frac{1}{100000}$ c.c. and with the blood of a rat which was killed by inoculation with the same culture and also with the faeces of infected fleas. The same culture diluted 1-100 was only active when five fleas had previously inflicted their bites on the place to which the culture was applied.

Animals used for control which were shaved in exactly the same way and to whose skin the same materials were applied, but who had not been previously bitten by fleas, all remained unaffected. Moreover, if the infectious material was applied to rats 24 hours after the bites had taken place no infection was caused, however many fleas had been applied to the rat. It is apparent therefore that the healing of the skin which takes place in the first 24 hours is sufficient to protect the animal.

The following experiment was undertaken to determine how long after feeding on a septicaemic animal the fler is able to communicate infection. We have already shown that the plague microbe remains in the flea up to six days.

\section{Experiment $X X V I I I$.}

Thirty of each of the four species of flea were applied to rats dying of plague in lots of 10 each. After 24 hours each lot of 10 fleas was fed on a healthy rat; this proceeding was continued for six days and each day fresh rats were used. The results obtained were as follows:

1. Typhlopsylla musculi. Out of three healthy rats bitten by fleas 24 hours after their own infection, one died. Out of three rats which were bitten by the same fleas 24 hours later, all remained alive. After another 24 hours one of the rats died. All the rats which were bitten after a longer interval remained alive.

2. Pulex canis. Three rats which were bitten by fleas 24 hours after infection remained alive. Out of three rats bitten by the same 


\section{Reports on Plague Investigations in India}

fleas after another 24 hours, one died 68 hours after being bitten. Only negative results were obtained when the bites took place at a later period up to five days.

3. Puleic felis. Out of three rats bitten by fleas 24 hours after infection, one died after six days. After two days, one of the rats was infected and died. After three days and later no infection could be obtained.

4. Pulex irritans. No infection was obtained after 24 hours or 48 hours. The same fleas however infected one of three rats on the third day ; later experiments gave negative results.

It follows therefore that fleas containing plague microbes can during the first three days infect healthy rats, but that after three days from infection the fleas were not capable of conveying the disease.

The following experiments were undertaken in order to determine what was the minimal number of infected fleas necessary to infect a healthy rat.

\section{Experiment $X X I X$}

Several series of rats, 10 in each series, were treated with infected fleas of $P$. canis in the following way:

To each rat of the first series two were applied.

To each rat of the second series three were applied.

To each rat' of the third series four were applied.

To each rat of the fourth series five were applied.

Rats belonging to the first three series all remained alive. From the rats belonging to the fourth series one died after 78 hours and one after 82 hours. This indicates that even when the plague microbe contained in infected fleas is highly virulent no infection is likely to take place when their number is less than five.

\section{Part II. Experiments with Bugs.}

These experiments were conducted with guinea-pigs. The plague culture used came from Batum, but its virulence was enhanced by passing it several times through guinea-pigs. The bugs used were Cimex lectularius which is the usual domestic parasite. The strong irritation occasioned by its bite is caused by the action of its saliva which it injects into the wound. Though it is chiefly a human parasite it will nevertheless quite willingly bite mice, rats and guinea-pigs, but only if the skin of these animals is shaved on the place to which the bug is applied. 
The bugs were contained in test tubes and were applied to the guineapigs by reversing the tube.

A bug never inflicts more than one bite and does not leave the place until it has filled itself with blood; its body under these conditions acquires an egg-shaped form. It is easy to judge what an enormous quantity of blood it can take in in comparison to its size by crushing it between two microscopical slides. One obtains enough liquid to smear the surface of both glasses, whilst the crushing of a starving bug leaves only small transparent spots.

The first thing to determine was whether bugs which had sucked the blood of an infected animal contained plague microbes. The experiments were conducted in exactly the same way as those with fleas.

\section{Experiment $X X X$.}

Bugs which had not been fed for 24 hours were applied to an infected guinea-pig dying of plague. Immediately after feeding some of them were crushed between two glasses and the contents of their bodies spread over the slides. These were fixed and stained for microscopical examination. Some of the bugs were also put into test tubes with broth, one into each, and crushed with a sterilised glass rod. The test tubes were afterwards placed in the thermostat.

On examining the film preparations one could observe amongst perfectly preserved blood corpuscles a considerable number of plague microbes which exhibited the usual bi-polar staining. The cultures obtained from crushed bugs were not pure but contained cocci in addition to plague bacilli. The latter were separated by plating and identified.

Two guinea-pigs were infected; one by inoculation with a pure culture obtained as above, another with the contents of five infected bugs. Both guinea-pigs died and the post-mortem examination of them gave a characteristic picture of plague. It follows therefore that bugs take in, together with the blood of the guinea-pigs, the plague microbe contained in the latter.

The following experiment was undertaken to determine how long the plague microbe existed in the bug and whether it lost its virulence under those conditions. As will be seen the result depends upon the length of the starvation to which the bugs were subjected previous to feeding on an infected animal. The longer the previous starvation, the longer was the time during which the plague microbe could be recovered, 
and vice versa. In the case of bugs which had not been starved before their infection or only starved for a short time, the plague microbe was only recovered for a short period.

\section{Experiment $X X X I$.}

Ten series of bugs, 50 in each series, were starved :-
(1) For 24 hours.
(2) For 7 days.
(3) For 2 weeks.
(4) For 3 weeks.
(5) For 1 month.
(6) For 2 months.
(7) For $2 \frac{1}{2}$ months.
(8) For 3 months.
(9) For 4 months.
(10) For $4 \frac{1}{2}$ months.

At the end of the period of starvation the bugs of each series were fed upon septicaemic guinea-pigs inoculated with a plague culture of which the M.L.D. was $\frac{1}{1000000}$ c.c. of a 24 hours' broth culture; they were afterwards examined in the following manner. Five bugs were taken daily during 10 days. One of them was crushed between two slides and prepared for microscopical examination, another was crushed on a watch glass by a sterilised glass rod and its contents aspirated into a pipette, inoculated into broth and incubated for 24 hours. The last three bugs were also crushed on a watch glass and their contents, with the addition of a small quantity of physiological salt solution, were used for inoculating guinea-pigs.

These experiments were continued for five months. Bugs were chosen of the same size and each was placed separately into a small test tube. They were applied to the guinea-pigs in these test tubes after which they were placed in a cupboard at $16-18^{\circ} \mathrm{C}$. The results will be seen in Table XI.

The plague microbe could be recovered after from one to two days if the bug had been starved from one to seven days before feeding upon an infected guinea-pig. If it had been kept starving from fourteen to thirty days the plague bacillus could be detected up to the third day. After thirty days or ninety days starvation the microbe was found to be still present on the sixth day, and after a period of starvation of four to four and a half months it could still be found on the eighth day ${ }^{1}$.

1 In Nuttall's experiments (Centralbl. f. Baht. xxIr. (1897), p. 92) Cimex lectularius which had starved for three months were fed on septicaemic plague mice. The bugs were kept at $20^{\circ} \mathrm{C}$. and their contents injected at intervals into mice. Virulent bacilli survived for 72 hours (but not for 120 hours) in the bugs. Smear preparations of the gut contents of the bugs made 24 hours after feeding on infected blood revealed an almost pure culture 
The guinea-pigs presented at the post-mortem the characteristic picture of bubonic plague with haemorrhagic infiltration at the place of inoculation, bubo and enlargement of the cervical and axilliary glands. The bubo was the size of a pea or small bean, of a deep red colour in the guinea-pigs which had died early, and of a yellowish tinge in those which had died late. The kidneys were enlarged with a great number of grey points under the capsule, and the liver was enlarged and dark or yellowish. In the blood and organs a large number of plague microbes were present.

The microscopical investigation of crushed infected bugs revealed that the plague microbes preserved their morphological characteristics during all the time that they were found in the bodies of the bugs.

The preparations from crushed bugs of the first two series were, up to the second day after their infection from guinea-pigs, identical with the preparations obtained from the blood of these guinea-pigs; in the midst of a great mass of well preserved blood corpuscles could be seen an enormous quantity of plague microbes in almost pure culture. After two days no blood corpuscles could be detected in the preparations of the infected bugs, and the number of plague microbes decreased suddenly and they were entirely absent in the preparations from bugs crushed three days or longer after infection. The same picture was presented by the preparations obtained from bugs which had been starved from 14 to 30 days before being fed on an infected guinea-pig (series 3,4,5), with the only difference that no plague microbes could be detected in them after four days, instead of three days, from the time of the infection. In the preparations from the bugs starved from two to four and a half months (series 6 to 10) before infection, the blood corpuscles of the guinea-pig were preserved much longer; they could be found on the third and even the fourth day after feeding on the infected guinea-pigs. The number of plague microbes found was highest at that time, and their number gradually decreased and disappeared entirely on the seventh day in series 6,7 and 8 , whilst in series 9 and 10 they continued to be found till the eighth day.

In these preparations from crushed infected bugs one could often find cells which contained plague microbes; these cells were the same size as the leucocytes of the guinea-pig and were like them, but for the fact that they contained a large number of vacuoles. Sometimes these

of $B$. pestis, but after 48 hours they appeared to be distinctly fewer in number and more saprophytes were present. The longer survival found by Dr Verjbitski is doubtless due to the lower temperature at which he kept his bugs. - Ed. 


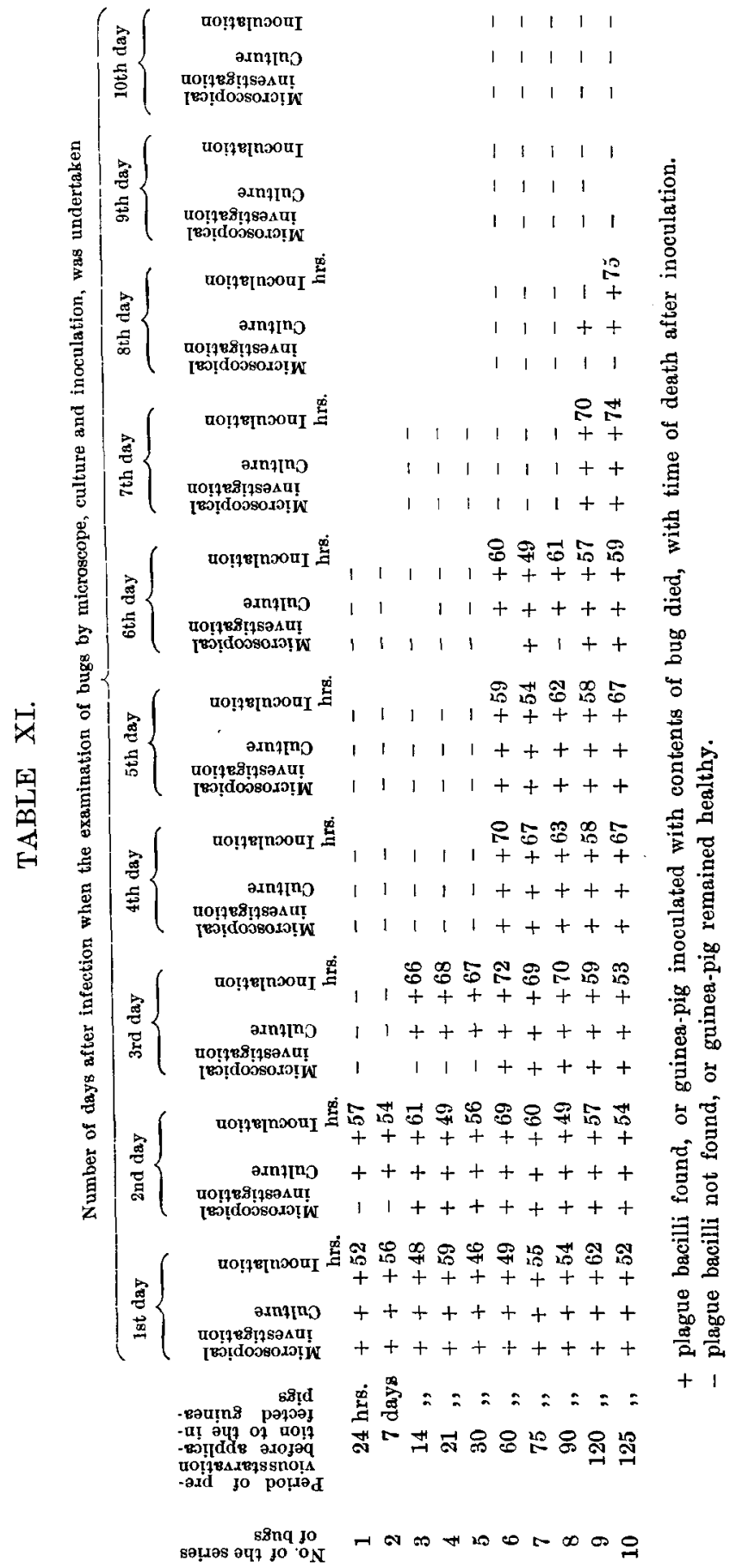


cells contained red blood corpuscles. At first I considered these cells to be the leucocytes of the blood of the guinea-pig. I found afterwards however that Tictin ${ }^{1}$ has described such cells in preparations made from bugs which had fed on human and monkey blood. Tictin considers them to be derived from the bugs, an opinion with which I am inclined to agree. This view is supported by the fact that these cells could be observed in preparations from bugs which had been starved for a considerable time, and also in preparations of infected bugs which had been crushed at a period after infection when red blood corpuscles of the guinea-pig could no longer be detected.

\section{Experiment $X X X I I$.}

This experiment was made to determine whether a sojourn in the alimentary canal of bugs affected the virulence of the organisms. Cultures were taken which had been obtained in Experiment XXXI from crushed infected bugs (series 9 and 10), one of which bugs had been crushed on the fifth, the others on the eighth day after infection. These cultures were tested on guinea-pigs. Three guinea-pigs were inoculated with $\frac{1}{100000}$ c.c. of the culture from the bug of series 9 and three from that of series 10. After inoculation with the first culture all three guinea-pigs died after 61,58 and 66 hours respectively; with the second culture two died, one after 57 and the other after 63 hours; the third remained alive. This proves that even a lengthy stay inside the body of the bug did not rob the plague microbes of their original virulence.

\section{Experiment $X X X I I I$.}

Three guinea-pigs were inoculated with a plague culture. Every six hours afterwards three bugs were allowed to feed on them. The bugs were immediately examined microscopically and by culture, as described in Experiment XXXI. At the same time the blood of the guinea-pig was examined microscopically.

The results are set out in Table XII from which it will be seen that as soon as bacilli were discoverable in the blood they were detected in the crushed bugs.

1 Materials for the Study of Relapsing Fever, Dissertation, 1898. 


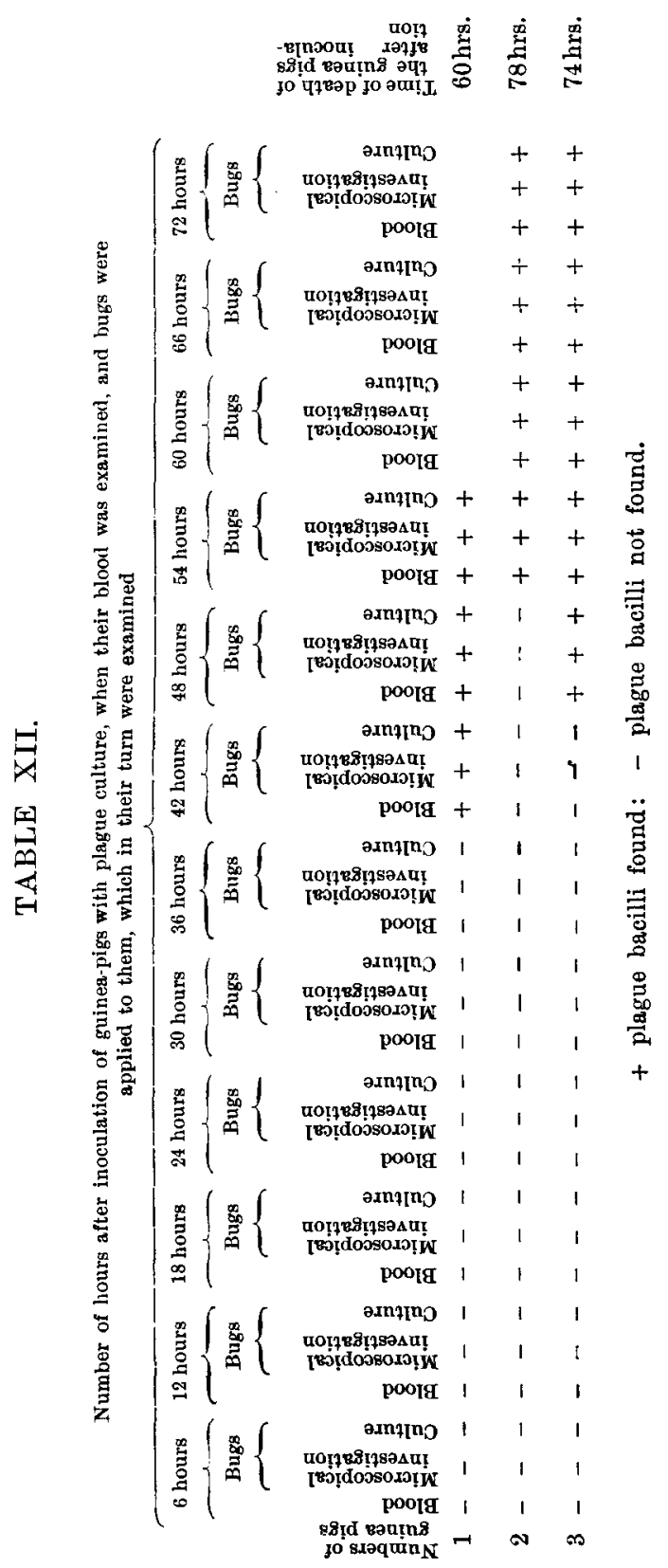




\section{Experiment $X X X I V$.}

Forty-two bugs which had been starved for two months were applied to an infected guinea-pig at a period of its illness when its blood on microscopical examination revealed the presence of only two or three bacilli in each field of vision. Two of these bugs were at once crushed and microscopical examination of their contents showed one or two plague bacilli in each field of vision. Of the remaining 40 bugs, 20 were placed in the thermostat at $28-30^{\circ} \mathrm{C}$. and 20 in the cupboard at $14-16^{\circ} \mathrm{C}$. Four of each lot were crushed each day. After 24 hours the microscopical investigation showed that the number of plague microbes had increased, there being now five to six in each field of vision in the case of those kept at $14-16^{\circ} \mathrm{C}$., and in those kept in the thermostat 10 to 15 . The same quantity of microbes was found in the preparations of bugs examined two days after infection. After three days the number of bacilli began to diminish, preparations from four bugs which had been kept at room temperature showing two to three in each field, and those kept in the thermostat five to six. Still fewer could be found in preparations made on the fourth day, and on the fifth day they could rarely be found.

Plague bacilli evidently multiply in the intestines of the bug. In those cases where the bugs had been weakened by starvation and in which the blood was only slowly digested, the plague microbes were found to persist for a longer time (Experiment XXXI).

\section{Experiment $X X X V$.}

Twelve bugs which had been starved for a month were fed on an infected guinea-pig, two were crushed at once and plague microbes were found under the microscope. Of the remaining bugs five were put into the thermostat, and five into a cupboard at $14-16^{\circ} \mathrm{C}$. All were alive after two months so that the feeding on infected blood does not appear harmful to the insects themselves.

The following experiments were made to discover whether the faeces of the infected bugs contained plague microbes. Infected bugs were kept in small sterilised test tubes. Their faeces accumulated on the walls of these tubes in the form of black specks, sometimes $1 \mathrm{~mm}$. in diameter. They were semi-liquid immediately after feeding on the animal, but if no further feeding occurred became less in quantity and ultimately ceased. 


\section{Experiment $X X X V I$.}

Four bugs previously starved for more than a month were applied to a dying guinea-pig, each in a separate test tube; on the following day they were each placed into a fresh test tube and their faeces investigated in the following way. The faeces of one bug were dissolved by a few drops of sterilised distilled water on a platinum wire. Samples were examined microscopically and also inoculated into broth. The excretions of the remaining three bugs were dissolved in 0.5 c.c. of sterilised distilled water and injected subcutaneously into three white mice and two guinea-pigs, $0 \cdot 1$ c.c. into each. The microscopical examination revealed five to seven plague microbes in each field of vision. Other bacilli were also present in these preparations and some large cocci. A pure culture of plague was obtained with difficulty by plating; all the animals inoculated with this culture died and at autopsy presented the ordinary picture of plague. Pure cultures of Bacillus pestis were obtained from the blood and organs.

The excretions of the same bugs 48 hours after their infection were investigated in the same manner both microscopically and by culture. A smaller number of plague microbes was observed. Two white mice and two guinea-pigs were inoculated, which all died from plague.

In the excretions on the third day the number of plague microbes was very small, and out of two mice and two guinea-pigs used for inoculation, one guinea-pig died after 77 hours. On the fourth and fifth days the faeces were free from plague bacilli.

This experiment proves that the excretions of bugs, which had been kept starving for a month previously to being fed on infected animals, contained virulent plague microbes for three days after feeding.

\section{Experiment $X X X V I I$.}

Bugs were fed upon a guinea-pig which had been inoculated with a plague culture, of which the M.L.D. was $\frac{1}{1000000}$ c.c. This animal subsequently succumbed to plague. The culture obtained from the faeces of the bugs on the third day after their infection was tested for virulence. To this end four guinea-pigs were inoculated subcutaneously with $\frac{1}{1000000}$ c.c. of a 24 hours' growth in broth. Two of them died after 70 and 74 hours respectively, and one remained alive. The plague microbe therefore retains its virulence after passing through the intestine of the bug, as noted by Nuttall. In no case did the microbes

Journ. of Hyg. virI 
in preparations from crushed bugs present any morphological change or alteration in staining.

The next series of experiments had as their object the determination of how far infected bugs may be capable of producing infection through their bites.

\section{Experiment $X X X V I I I$.}

Ten bugs, before they had absorbed as much blood as they wanted from an infected animal, were removed and applied immediately to a healthy guinea-pig.

In five experiments in which the original guinea-pigs had been inoculated with a culture of low virulence not one of the fresh animals died nor fell ill, though the bugs were found to contain plenty of plague microbes on microscopical examination.

The first positive result was obtained when the guinea-pigs used for infecting the bugs were themselves infected by a culture of which the minimal lethal dose corresponded to $\frac{1}{800000}$ c.c. Using a guinea-pig infected with a culture of this virulence, ten bugs were applied to each of fifteen healthy guinea-pigs. After 63 hours one of these guinea-pigs died, after 67 hours another. A pure culture of plague was obtained from their blood and organs. Thirteen guinea-pigs remained alive.

This experiment was repeated when the virulence of the culture had reached $\frac{1}{1000000}$ c.c. Of 26 guinea-pigs used for this experiment, four died in from 56 to 73 hours after the bugs had been allowed to bite them.

This comparatively small percentage of positive results increased suddenly when the infected bugs were applied to the ear instead of the hind leg of the guinea-pigs ${ }^{1}$. The surface of the ear was carefully shaved, it was taken hold of with two fingers, and a test tube which contained the infected bugs was reversed with the opening downwards on to the upper shaved surface of the ear. In this experiment 10 infected bugs were again applied to each guinea-pig. Altogether 25 guinea-pigs were used, of which seven died from plague. There was no local reaction on the spot where the infection had entered the guinea-pig's body when the bites were inflicted on the ear.

Further experiments were undertaken to determine:-

Firstly, what was the smallest number of infected bugs which could bring about infection.

\footnotetext{
1 Nuttall (1897, p. 92) made four experiments with mice with negative results : two to ten bugs were applied at the root of the tail.-Ed.
} 
Secondly, how long bugs retained the power of infecting through their bites, and

Thirdly, if it was possible to infect several animals by means of the same infected bugs.

\section{Experiment $X X X I X$.}

One infected bug was, immediately after having fed on an infected guinea-pig, applied to each of the first series of healthy guinea-pigs. Two bugs were applied to each of the next series, etc., so as to determine the minimal number of bugs capable of infecting a healthy animal with plague. Each series consisted of five guinea-pigs. The bugs were applied to the skin of the left ear.

All the guinea-pigs belonging to the first and second series remained alive. One guinea-pig from the third series died after 64 hours. Four infected bugs were applied to each of the following two series. Three guinea-pigs died out of the 10 , one after 53 hours, the second after 64 hours, and the third after 79 hours. Post-mortem examination showed in all three guinea-pigs, and in the guinea-pig belonging to the third series, a characteristic picture of plague. There was an insignificant subcutaneous infiltration on the place of the bite in the last named animal; the others did not show any traces of skin injury to indicate the place through which the infection had entered the body.

The smallest number of infected bugs which can transmit infection and cause the death from plague of a healthy animal appears therefore to be three.

\section{Experiment $X L$.}

This experiment was undertaken in order to ascertain how long infected bugs are capable of transmitting infection through their bites. Ten series of bugs which had been allowed to starve for about four months were applied to guinea-pigs dying from plague. There were 25 bugs in each series. Five of the infected bugs of the first series were applied to each of five healthy guinea pigs three days after infection. Of the second series, again five bugs were applied to each of five guinea-pigs four days after infection; the bugs of the third series were treated in the same way after five days, of the fourth series after six days, of the sixth series after seven days, etc.

Two guinea-pigs died from the bites of the bugs belonging to the first series, one after 49 hours, the other after 50 hours. One guineapig died from the bites of the bugs belonging to the second series 
after 51 hours. The bites of the bugs belonging to the remaining series did not give any positive results, which allows us to conclude that the bug will not transmit infection after five days from the time when it had bitten an infected animal. All the bugs in this experiment were applied to the ear of the guinea-pigs.

The following experiment was undertaken with a view to determine whether several guinea-pigs could be infected through the bites of the same bugs.

\section{Experiment $X L I$.}

A guinea-pig was infected with a culture of which the M.L.D. was $\frac{1}{20000000}$ c.c. The guinea-pigs used in the previous experiment had been infected with the same culture. Thirty bugs which had previously been starved for two months were fed on the guinea-pig. On each of the following days, five bugs were applied to the ear of each of six healthy guinea-pigs, taking fresh animals each day. When fed on the infected animals the bugs were not allowed to take as much food as they would have liked to do, as I found that if they were allowed to do so they would not bite at all, or only unwillingly, on the next day. Two guinea-pigs out of six which were bitten by the bugs immediately after infection died after 50 hours; the bites of the same bugs 24 hours later killed one guinea-pig after 58 hours. All three guinea-pigs undoubtedly died of plague. The condition of the ear in all three was perfectly normal; the anatomical examination showed an ordinary picture of plague and the blood and organs and bubo were full of plague microbes. Further applications of the same bugs to guinea-pigs on the following days gave no results.

This indicates that the same infected bugs cannot convey plague infection more than twice in the course of the first and second day; and that they were not able to infect on the third or fourth day, notwithstanding that they still contained plague microbes on the fifth day.

Under natural conditions the bug causes irritation of the skin by crawling, and is often crushed on the place where it inflicts its bite, thereby spreading its contents on both the skin and the clothing. A bug is much more easily crushed than a flea, especially when it is full of blood. Favourable conditions would therefore be created for plague microbes to penetrate any cracks in the skin. The following experiment was undertaken to investigate this point. 


\section{Experiment XLII.}

The inner surface of the hind legs of six guinea-pigs was slightly scratched three times with a very fine needle and the contents of crushed infected bugs were spread over the place. The bugs used for the first three guinea-pigs were erushed 24 hours after their infection. Those used for the second series of three guinea-pigs had been infected four days previously. The bugs had been kept starving for about two months before applying them to the infected guinea-pig. All the six guinea-pigs died of plague 47 to 69 hours after being subjected to this treatment.

\section{Experiment XLIII.}

One infected bug was applied to the shaved ear of each of ten guinea-pigs; five guinea-pigs received bugs which had been infected 24 hours previously, the remaining five were bitten by bugs four days after infection. Instead of using ordinary test tubes in this experiment I had small glass tubes open at both ends and stopped with cotton wool. The infected bug contained in one of these tubes was applied to the ear of the guinea-pig. When the bug became swollen with blood the cotton wool was removed from the further end of the tube and the bug crushed on the spot with a glass rod.

Seven of the 10 guinea-pigs died; all the five belonging to the first series, and two belonging to the second. A small amount of subcutaneous oedema and haemorrhagic infiltration were found in two of them at the situation of the bite, the remaining five had no local signs; buboes were present in the neck of the size of a small bean; the internal organs showed a typical appearance and, as well as the blood, contained enormous quantities of plague microbes.

This shows that the comparatively small percentage of plague infections transmitted through bug bites is considerably increased when the bugs are crushed on the skin of the animal bitten.

In the experiments with fleas it was shown that the injury to the skin' made by their bites is sufficient to allow plague microbes to gain entrance. The corresponding experiment was undertaken with bugs.

\section{Experiment $X L I V$.}

One uninfected bug was applied to the ear of each of 30 guineapigs. Different kinds of infectious plague material were immediately applied to the spots. In the first five pigs they were smeared with 
a 24 hours' broth culture; in the second five with the blood of an infected guinea-pig; in the third five with the faeces of infected bugs; in the fourth five with a broth culture diluted 1-100, and in the remaining ten partly with the blood of a guinea-pig which had died of plague and partly with a 24 hours' broth culture. In the case of the last ten, however, the applications were not made at once but 24 hours after the bites had been inflicted.

Two guinea-pigs which had been treated with the broth culture died after 49 and 57 hours. Two guinea-pigs treated with the blood of a dead infected animal and the excretions of infected bugs died, the former after 54 hours, the latter after 77 hours.

All the guinea-pigs in which the infective material was applied 24 hours after infliction of the bites remained alive. All dead guineapigs presented the characteristic picture of bubonic plague. Control animals were treated in exactly the same manner without having been previously bitten by bugs; they all remained alive.

This proves that the injury to the skin inflicted by the bites of bugs is sufficient to allow infectious material to penetrate into the organism, but that after 24 hours the little wound is entirely healed and no infection can penetrate through it.

The clothing of people who live in dirty unhygienic surroundings is generally covered with spots from crushed bugs and their faeces. It is possible that the plague microbes contained in these spots may be capable of transmitting infection, and it was therefore important to establish how long the plague microbes will preserve their vitality in these spots under different circumstances.

I began by trying the effect of drying the spots and the microbes contained in them, but this treatment seems to destroy them. Experiments with the faeces of infected fleas, and with fleas crushed on different fabrics, were undertaken at the same time.

\section{Experiment $X L V$.}

Bugs were applied to guinea-pigs dying from plague. When they were fully fed, a proportion of them were crushed with a glass rod inside a test tube and their contents were used to soil sterilised strips of linen, cotton, silk and woollen fabrics, half a centimetre wide; they were also spread over sterilised strips of the same size of filter and writing paper, glass slides and small pieces of pine wood. The remainder of the infected bugs was kept in sterilised glass basins, the bottom of which 


\section{Reports on Plague Investigations in India}

was covered respectively with filter and ordinary paper, linen, wool, cotton and silk fabrics. After three days the paper and materials were covered with the faeces of the insects in the form of black spots of different sizes.

The strips of materials and paper soaked with the contents of the infected bugs were cut into smaller pieces of about half a centimetre square and placed in Petri dishes. The slides and wood smeared with the same material were also placed in Petri dishes. The paper and various fabrics covered with faeces were cut into smaller pieces so as to have two or three spots on each piece, and these also were put into Petri dishes.

Pulex canis were after infection treated slightly differently; a few drops of sterilised water were introduced into the test tube and the fleas allowed to drown in it. After this they were placed between two glasses which had been previously covered on the surfaces facing each other with filter and writing paper, linen, silk and other fabrics, and crushed. The spots obtained from the crushed fleas were cut out and placed in Petri dishes. To obtain the faeces of fleas for investigation the inner surface of a test tube was lined with sterilised paper and various other fabrics. The fleas contained in these test tubes left their faeces on the fabrics and paper. These were treated in the same manner as those of the bugs.

In order to determine on the one hand the action of drying accompanied by the action of diffused light, Petri dishes containing the same material were placed in the thermostat at $28-30^{\circ} \mathrm{C}$. and in a dark and a light cupboard at room temperature $\left(14-16^{\circ} \mathrm{C}\right.$.). The dishes were not covered with lids but with dises of filter paper.

The investigations were conducted in the following manner: the pieces of material, after submission to the various treatments, were put into test tubes containing broth and incubated. If growth was present after 24 hours, a microscopical examination was made. If this revealed the undoubted presence of plague bacilli no further investigation was made. Where there was the slightest doubt plating was resorted to. If no growth of plague microbes could be detected after 24 hours, the tubes were left in the thermostat for a few more days after which the cultures obtained were examined both under the microseope and by plating. If no plague microbes could be detected on the ninth or tenth day, the result of the experiment was considered to be negative. The longer the previous drying process, the later the growth of the plague microbes occurred, appearing in some cases only on the fourth or fifth day. 
The saprophytes, which were mostly cocci, grew in broth earlier than the plague bacilli but they did not conceal or prevent the growth of the latter. When separated in pure culture and inoculated into broth at the same time as the plague microbe, they grew there side by side, each species retaining its vitality. Even in the case when plague microbes were put into broth in which there already was a growth of these cocci, the bacilli succeeded in growing. The results obtained in this experiment are illustrated by the following Table.

\section{TABLE XIII}

\begin{tabular}{|c|c|c|c|c|}
\hline \multirow{2}{*}{ Material used } & \multirow[b]{2}{*}{ Fabric } & \multirow[b]{2}{*}{ Thermostat $30^{\circ} \mathrm{C}$. } & \multicolumn{2}{|c|}{ Room temperature } \\
\hline & & & $\begin{array}{c}\text { Dark } \\
\text { cupboard }\end{array}$ & $\begin{array}{c}\text { Diffused } \\
\text { light }\end{array}$ \\
\hline \multirow[t]{8}{*}{ Crushed infected bugs } & Linen & 4 & 45 & 42 \\
\hline & Cotton material & 3 & 20 & 19 \\
\hline & Silk $\quad$, & 3 & 16 & 18 \\
\hline & Wool $\quad$, & 4 & 18 & 18 \\
\hline & Filter paper & 2 & 18 & 15 \\
\hline & Writing , & 2 & 7 & 5 \\
\hline & Glass & 2 & 6 & 6 \\
\hline & Wood & 3 & 11 & 8 \\
\hline \multirow[t]{7}{*}{ Faeces of infected bugs } & Linen & 3 & 18 & 14 \\
\hline & Cotton material & 2 & 16 & 16 \\
\hline & Silk $\quad$, & $\mathbf{3}$ & 10 & 10 \\
\hline & Wool ", & 3 & 12 & 12 \\
\hline & Filter paper & 2 & 15 & 15 \\
\hline & Writing ,, & 2 & 5 & $\mathbf{3}$ \\
\hline & Glass & 1 & 6 & 5 \\
\hline \multirow[t]{7}{*}{ Crushed infected fleas } & Linen & $\mathbf{3}$ & 22 & 19 \\
\hline & Cotton material & $\mathbf{3}$ & 18 & 17 \\
\hline & Silk $\quad "$ & 2 & 17 & 13 \\
\hline & Wool , , & 2 & 18 & 18 \\
\hline & Filter paper & $\mathbf{3}$ & 16 & 16 \\
\hline & Writing " & 2 & 5 & 4 \\
\hline & Glass & 1 & 5 & 5 \\
\hline \multirow[t]{7}{*}{ Faeces of infected fleas } & Linen & 3 & 12 & 10 \\
\hline & Cotton material & 2 & 6 & 6 \\
\hline & Silk $\quad "$ & 2 & 7 & 7 \\
\hline & Wool & 3 & 7 & 4 \\
\hline & Filter paper & 2 & 6 & 5 \\
\hline & Writing , & 1 & 6 & 4 \\
\hline & Glass & 1 & 6 & 5 \\
\hline
\end{tabular}

The numbers indicate days of survival of the bacilli.

The fact that the microbes contained in the spots from crushed fleas died sooner than those contained in the spots from crushed bugs can be explained by the difference in the depth of the layer in these 
spots; the fabrics treated with crushed bugs were soaked, whilst the crushing of the fleas only left traces on the surface. The additional moisture in the first case provided more favourable conditions for the life of the bacillus. Even in spots from crushed fleas and their faeces, plague microbes remained alive during a considerable time, longer on linen, silk, cotton and wool fabrics and filter paper (16 to 22 days) than on glass and writing paper ( 5 days).

It is clear therefore that spots from crushed infected fleas, bugs and their excretions can at an ordinary temperature contain plague microbes during 18 to 45 days, and it is easy to realise the danger presented by the underclothing of patients ill with plague with regard to infection, if plague microbes can preserve their vitality on drying for a month, i.e. under the most unfavourable circumstances. It is natural to suppose that in moist surroundings they will live still longer.

\section{Experiment XLVI.}

In this experiment the same materials as were used in Experiment XLV were placed in glass dishes which, in their turn were placed open into large Koch dishes, at the bottom of which was sterilised water up to the height of 1 centimetre to prevent drying. This was replaced as it evaporated. Some of the dishes were covered with lids and placed in the thermostat, others were kept in the dark cupboard, and others exposed to diffused light at room temperature, others again in the cold cupboard at $4^{\circ}$ to $5^{\circ} \mathrm{C}$. The examination of materials treated in this way took place every three days in the same way as in the last experiment.

\begin{tabular}{|c|c|c|c|c|c|}
\hline \multirow[b]{2}{*}{ Material used } & \multirow[t]{2}{*}{ TABL } & \multirow[b]{2}{*}{$\begin{array}{l}\text { Thermostat } \\
28^{\circ}-30^{\circ} \mathrm{C} .\end{array}$} & \multicolumn{2}{|c|}{$\begin{array}{c}\text { Room temperature } \\
14^{\circ}-18^{\circ} \mathrm{C}\end{array}$} & \multirow{2}{*}{$\begin{array}{c}\text { Cold } \\
\text { cupboard } \\
4^{\circ}-5^{\circ} \mathrm{C} .\end{array}$} \\
\hline & & & $\overparen{\begin{array}{c}\text { Dark } \\
\text { cupboard }\end{array}}$ & $\begin{array}{c}\text { Diffused } \\
\text { light }\end{array}$ & \\
\hline \multirow[t]{7}{*}{ Crushed infected bugs } & Linen & 30 & 141 & 130 & 168 \\
\hline & Cotton material & 30 & 135 & 120 & 162 \\
\hline & Silk $\quad$, & 28 & 130 & 130 & 162 \\
\hline & Wool , & 28 & 123 & 118 & 129 \\
\hline & Filter paper & 18 & 118 & 118 & 120 \\
\hline & Writing , & 18 & 99 & 90 & 120 \\
\hline & Glass & 18 & 99 & 93 & 120 \\
\hline \multirow[t]{7}{*}{ Faeces of infected bugs } & Linen & 18 & 33 & 30 & 48 \\
\hline & Cotton material & 12 & 33 & 33 & 36 \\
\hline & Silk $\quad$, & 12 & 21 & 18 & 39 \\
\hline & Wool & 9 & 21 & 21 & 48 \\
\hline & Filter paper & 12 & 18 & 18 & 18 \\
\hline & Writing , & 12 & 18 & 12 & 12 \\
\hline & Glass , & 9 & 18 & 12 & 18 \\
\hline
\end{tabular}




\begin{tabular}{|c|c|c|c|c|c|}
\hline \multirow{4}{*}{$\begin{array}{c}\text { Material nsed } \\
\text { Crushed infected fleas }\end{array}$} & \multirow[b]{2}{*}{ Fabric } & \multicolumn{3}{|c|}{ 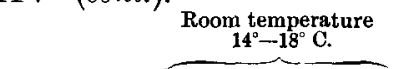 } & \multirow[b]{2}{*}{$\begin{array}{c}\text { Cold } \\
\text { cuppoard } \\
4^{\circ}-5^{\circ} \mathrm{C} .\end{array}$} \\
\hline & & $\begin{array}{l}\text { Thermostat } \\
28^{\circ}-30^{\circ} \mathrm{C} \text {. }\end{array}$ & $\begin{array}{c}\text { Dark } \\
\text { cupboard }\end{array}$ & $\widehat{\substack{\text { Diffused } \\
\text { light }}}$ & \\
\hline & Linen & 42 & 121 & 121 & 159 \\
\hline & Cotton material & 42 & 121 & 105 & 159 \\
\hline \multirow{11}{*}{ Faeces of infected fleas } & Silk $\quad$, & 28 & 105 & 105 & 115 \\
\hline & Wool & 39 & 118 & 121 & 159 \\
\hline & Filter paper & 21 & 99 & 99 & 121 \\
\hline & Writing ," & 21 & 90 & 90 & 105 \\
\hline & Glass & 21 & 93 & 81 & 99 \\
\hline & Linen & 15 & 24 & 24 & 33 \\
\hline & Cotton material & 15 & 18 & 12 & 39 \\
\hline & Silk $\quad \#$ & 9 & 18 & 9 & 33 \\
\hline & Wool $\quad "$ & 12 & 21 & 12 & 27 \\
\hline & Filter paper & 12 & 18 & 9 & 18 \\
\hline & Writing ," & 9 & 18 & 12 & 18 \\
\hline
\end{tabular}

The numbers indicate days of survival of the bacilli.

The action of direct sunlight and of freezing on the microbes contained in these stains was next investigated.

\section{Experiment XLVII.}

The investigation of the action of direct sunlight was undertaken in the beginning of June. Material treated in the same way as in the two previous experiments was exposed to the direct rays of the sun in Petri dishes from 11 a.m. to 5 p.m. Every half hour from the beginning of the experiment, bits of the fabrics, paper, glass, etc. were taken out and put into broth. In the cases where the plague microbes had not died after one day's exposure they were exposed again on the following days, weather permitting. The thermometer was placed in the dishes which contained the material under investigation. I did not undertake any precautions to prevent the preparations getting heated by the sun, therefore my preparations were dried by the sun whilst exposed to its rays.

TABLE XV.

\begin{tabular}{|c|c|c|c|c|c|}
\hline \multirow[b]{2}{*}{ Fabric } & \multirow[b]{2}{*}{ Temperature } & \multicolumn{4}{|c|}{ Hours of survival in direct sunlight } \\
\hline & & $\begin{array}{c}\text { Spots from } \\
\text { crushed bugs } \\
\text { Hours }\end{array}$ & $\begin{array}{l}\text { Spots from } \\
\text { their faeces } \\
\text { Hours }\end{array}$ & $\begin{array}{l}\text { Spots from } \\
\text { crushed fleas } \\
\text { Hours }\end{array}$ & $\begin{array}{c}\text { Spots from } \\
\text { their faeces } \\
\text { Hours }\end{array}$ \\
\hline Linen & $38-46^{\circ} \mathrm{C}$. & 12 & $6 \frac{1}{2}$ & $9 \frac{1}{2}$ & 5 \\
\hline Cotton material & 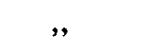 & $8 \frac{1}{2}$ & 5 & 6 & 5 \\
\hline Wool , , & , & 9 & $4 \frac{1}{2}$ & 6 & $3 \frac{1}{2}$ \\
\hline Silk $\quad$, & $36-41^{\circ} \mathrm{C}$. & $6 \frac{1}{2}$ & 5 & $5 \frac{1}{2}$ & $4 \frac{1}{2}$ \\
\hline Filter paper & , & $2 \frac{1}{2}$ & $1 \frac{1}{2}$ & 2 & 1 \\
\hline Writing , & $40^{\circ} \mathrm{C}$. & $2 \frac{1}{2}$ & 1 & $1 \frac{1}{2}$ & $1 \frac{1}{2}$ \\
\hline Glass & , & $2 \overline{1}$ & 1 & $1 \overline{1}$ & 1 \\
\hline
\end{tabular}




\section{Experiment $X L V I I I$.}

To investigate the influence of freezing on plague microbes on the same materials, they were placed in Petri dishes wrapped in thick black paper and put outside the window in the winter. All the materials were examined daily. The temperature to which the dishes were exposed was from $-5^{\circ}$ to $-18^{\circ} \mathrm{C}$.

TABLE XVI.

\begin{tabular}{lccccc}
\multicolumn{1}{c}{ Fabric } & Temperature & $\begin{array}{c}\text { Spots from } \\
\text { crushed bugs } \\
\text { Days }\end{array}$ & $\begin{array}{c}\text { Spots from } \\
\text { their faeces } \\
\text { Days }\end{array}$ & $\begin{array}{c}\text { Spots from } \\
\text { crushed fleas } \\
\text { Days }\end{array}$ & $\begin{array}{c}\text { Spots from } \\
\text { their faeces } \\
\text { Days }\end{array}$ \\
Linen & -5 to $-18^{\circ}$ C. & 16 & 9 & 12 & 9 \\
Cotton material &,, & 14 & 9 & 12 & 7 \\
Wool ", &, & 14 & 10 & 9 & 9 \\
Silk ", &, & 11 & 9 & 10 & 7 \\
Filter paper &, & 9 & 8 & 6 & 7 \\
Writing ", &, & 8 & 7 & 6 & 5 \\
Glass &,, & 6 & 4 & 5 & 5
\end{tabular}

We see therefore that plague microbes in the faeces of these insects remain alive from four to 16 days at a temperature of from $-5^{\circ}$ to $-18^{\circ} \mathrm{C}$.

It was next ascertained whether the virulence of the plague bacilli was preserved unaltered under the influence of these surroundings.

Pure cultures of plague were prepared from the following sources:

(1) Crushed infected bugs on bits of linen :-

(a) Dried during 35 days at room temperature.

(b) Kept during 130 days in damp surroundings at a temperature of $4^{\circ}-5^{\circ} \mathrm{C}$.

(c) Exposed during 8 days to direct sunlight.

(d) Frozen during 10 days at a temperature of $-5^{\circ}$ to $-18^{\circ} \mathrm{C}$.

(2) From crushed infected fleas on linen after:-

(a) Drying during 15 days at room temperature.

(b) After being kept 120 days in damp surroundings.

(c) Exposed for 6 hours to direct sunlight.

(d) Frozen during 7 days at $-5^{\circ}$ to $-18^{\circ} \mathrm{C}$.

(3) From the faeces of bugs which had been allowed to dry on linen at room temperature during 10 days.

(4) From the faeces of fleas on the same fabric which were kept in damp surroundings at a temperature of $41^{\circ}-5^{\circ} \mathrm{C}$. for 15 days. 
All the above cultures were tested for their virulence by inoculating guinea-pigs (cultures obtained from bugs) or rats (cultures obtained from fleas).

The guinea-pigs which had served originally to infect the bugs had been inoculated with a culture of which the M.L.D. was $\bar{\Sigma} \frac{1}{00} \overline{0} \overline{0}$ c.c. to $\frac{1}{4000000}$ c.c.; the rats which served to infect the fleas had been inoculated

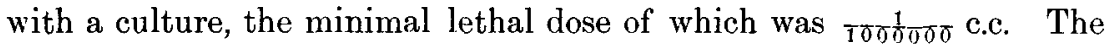
cultures obtained from the various materials above mentioned were tested for virulence by inoculating guinea-pigs and rats with a gradually increasing dose. The results were as follows:-

In the case of cultures from linen soiled with crushed bugs and fleas or the faeces of these insects which had been exposed for six to seven hours to the action of direct sunlight, the minimum fatal dose for guinea-pigs was $\frac{1}{10000}$ c.c. (death on the fourth to eighth day), and for rats 201500 c.c. (death on the fifth to ninth day). Cultures from the same materials upon linen which had been exposed for seven to 10 days to a temperature of $-5^{\circ}$ to $-18^{\circ} \mathrm{C}$. killed guinea-pigs in the dose of $\frac{1}{50000}$ c.c., and rats in the dose of $\frac{1}{250 \pi 00}$ c.c. The virulence of the organism which had dried gradually during 15 to 35 days at room temperature was much better preserved. These cultures killed

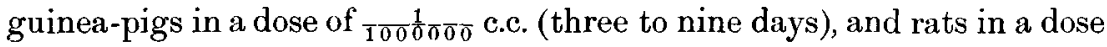
of $\frac{1}{250000}$ c.c. (on the sixth day). The virulence decreased least in spots on linen which was kept damp in the cold cupboard $\left(3^{\circ}\right.$ to $5^{\circ} \mathrm{C}$.). Cultures obtained from these killed guinea-pigs at $\frac{1}{1500000}$ c.c., and rats at $\frac{1}{50000}$ c.c. The guinea-pigs died after three to five days, the rats after four to six days.

From the results one must conclude that clothing and bed clothes which are covered with material from infected insects, obtained either by crushing them or from their faeces, can serve during a long time as a source of infection.

Disinfectants. Experimenting with the ordinary chemical disinfectants I found that corrosive sublimate $0 \cdot 1$ per cent., phenol 5 per cent. or formalin 1 per cent. kill plague bacilli in the above fabrics, in squashed bugs or fleas, or in the blood of infected animals in ten or fifteen minutes. They also kill fleas at once, but do not destroy plague bacilli within the fleas for three to four hours. Even 02 per cent. sublimate takes 2 to $2 \frac{1}{2}$ hours to penetrate the flea. Formalin vapour is a poor insecticide especially with bugs. 


\section{Reports on Plague Investigations in India}

\section{Summary of Results.}

(1) All fleas and bugs which have sucked the blood of animals dying from plague ${ }^{1}$ contain plague microbes.

(2) Fleas and bugs which have sucked the blood of animals which are suffering from plague only contain plague microbes when the bites have been inflicted from 12 to 26 hours before the death of the animals, that is, during that period of their illness when their blood contains plague bacilli.

(3) The vitality and virulence of the plague microbes are preserved in these insects.

(4) Plague bacilli may be found in fleas from four to six days after they have sucked the blood of an animal dying with plague. In bugs, not previously starved or starved only for a short time (one to seven days), the plague microbes disappear on the third day; in those that have been starved for 4 to $4 \frac{1}{2}$ months, after eight or nine days.

(5) The numbers of plague microbes in the infected fleas and bugs increase during the first few days.

(6) The faeces of infected fleas and bugs contain virulent plague microbes as long as they persist in the alimentary canal of these insects.

(7) Animals could not be infected by the bites of fleas and bugs which had been infected by animals whose own infection had been occasioned by a culture of small virulence, notwithstanding the fact that the insects may be found to contain abundant plague microbes.

(8) Fleas and bugs that have fed upon animals which have been infected by cultures of high virulence convey infection by means of bites, and the more certainly so the more virulent the culture with which the first animal was inoculated.

(9) The local inflammatory reaction in animals which have died from plague occasioned by the bites of infected insects is either very slight or absent. In the latter case it is only by the situation of the primary bubo that one can approximately identify the area-through which the plague infection entered the organism.

(10) Infected fleas communicate the disease to healthy animals for three days after infection. Infected bugs have the power of doing so for five days.

1 That is, if a septicaemia is present. Dr Verjbitski does not appear to have had the experience that rats may die of plague without developing a septicaemia sufficiently extensive to infect the flea : this not infrequently occurs especially in cool climates.-Ed. 
(11) It was not found possible for more than two animals to be infected by the bites of the same bugs.

(12) The crushing of infected bugs in situ during the process of biting, occasioned in the majority of cases the infection of the healthy animal with plague.

(13) The injury to the skin occasioned by the bite of bugs or fleas offers a channel through which plague microbes can easily enter the body and occasion death from plague.

(14) Crushed infected bugs and fleas and their faeces, like other plague material, can infect through the small punctures of the skin caused by the bites of bugs and fleas, but only for a short time after the infliction of these bites.

(15) In the case of linen and other fabrics soiled by crushing infected fleas and bugs on them, or by the faeces of these insects, the plague microbes can under favourable conditions remain alive and virulent during more than five months.

(16) Chemical disinfectants do not in the ordinary course of application kill plague microbes in infected fleas and bugs.

(17) The rat flea Typhlopsylla musculi does not bite human beings.

(18) Human fleas do bite rats.

(19) Fleas found on dogs and cats bite both human beings and rats.

(20) Human fleas and fleas found on cats and dogs can live on rats as casual parasites, and therefore can under certain conditions play a part in the transmission of plague from rats to human beings, and vice versa.

\section{Epidemiological Significance of the Results obtained.}

The results described above show that the part played by insects in the epidemiology of plague must be considerable. Taking into consideration on the one hand how difficult it is to bring about the infection of a rat through the digestive canal, and on the other hand the ease with which the plague microbe penetrates through the most insigniticant scratches on the skin, the transmission of infection from one animal to another through the agency of rat fleas, which leave a dead and infected rat to go and live on other healthy rats, to whom they in turn communicate plague infection, affords a perfectly satisfactory explanation of plague epidemics amongst rats. 


\section{Reports on Plague Investigations in India}

This supposition is proved by the facts

(1) that all fleas found on rats which die of plague contain plague microbes ${ }^{1}$;

(2) that the bites of such fleas can occasion infection with plague in healthy animals when these fleas are artificially transferred on to fresh animals, and when this transference of infected fleas from a dead animal to a healthy one takes place voluntarily.

Concerning the communication of plague from rats to human beings, numerous observations have shown that cases of plague have been occasioned by people coming into contact with infected rats, for instance by touching them with their hands, and that it is more dangerous to touch warm corpses than those that had already become cold. Though rat fleas do not bite human beings ${ }^{2}$ still a certain number of the fleas of domestic animals may be present on rats, and under certain circumstances also human fleas which readily bite both men and rats.

During plague epidemics in China and India the buboes observed have been chiefly situated in the groin, which proves plainly that the infection must have chiefly entered the body through the legs and feet of individuals. In India where the native quarters are teeming with fleas it is, according to Blackmore, just the feet which suffer more than any other part of the body from bites.

Infection from man to man, except in the "pneumonic" variety, may no doubt be explained by the transmission of the plague infection through insects. The way in which bugs convey plague to man is probably the same as that suggested by Tictin in the case of relapsing fever. A bug which has not succeeded in filling itself with infected blood transfers itself to a healthy individual and forthwith bites again, thereby introducing any plague bacilli adherent to its proboscis. Or owing to the irritation it produces it may be crushed by the individual in his efforts to capture it, and the infective contents rubbed into the slight puncture occasioned by the bite.

Bugs which have sucked their full complement of blood do not as a rule bite again for a considerable interval, but if felt crawling upon the skin may be crushed in the same way. Should they contain plague bacilli these may be inoculated through any slight abrasion existing in the neighbourhood.

1 Dr Verjbitski presumably means in his experience. This was not by any means the case with the observations of the Commission.-Ed.

2 This is of course not true for the Indian rat flea $(P$. cheopis): see these reports Journal of Hygiene, vol. vir. (1897), p. 472.-Ed. 


\section{Plague Transmission by Insects}

Besides this direct part which infected insects can play in the spread of plague, the belongings and especially the linen of plague patients soiled by the faeces of these insects or their crushed bodies can serve as a possible source of plague infection during a long time. This may explain how clothes of people who have died of plague may transmit infection even months after their possessor's death. 